Teresa BUCZKOWSKA-MURAWSKA, Mariusz ŻOKOWSKI

Air Force Institute of Technology (Instytut Techniczny Wojsk Lotniczych)

\title{
USING THE TELEMETRY SYSTEM AS AN ELEMENT OF THE ENGINE OPERATION MONITORING SYSTEM OF UAS
}

\section{Stosowanie systemu telemetrycznego jako elementu systemu monitorowania pracy silnika BSP}

\begin{abstract}
The article presents an engineering approach that allows us to collect engine operation characteristics using built-in telemetry mechanisms, filled with the passive recording system. As a result of the development of the solution, the characteristics of the engine operation were obtained under real conditions, and the universal registration tool was built with a wider application than simply the registration of the engine operating parameters. The development of the solution allowed measurements to be obtained in a passive mode using a distributed architecture for engine monitoring and engine operation characteristics, which would be difficult to obtain and archive without logger production, especially during flight tests.
\end{abstract}

Keywords: engine, UAS, telemetry, logger

Streszczenie: W artykule przedstawiono podejście polegajace na dostosowaniu pasywnego systemu rejestracji pracy silnika do systemu telemetrycznego silnika w taki sposób, aby byt dla niego niewykrywalny. Jest to podejście inżynierskie, które pozwoliło na zebranie charakterystyk pracy silnika $w$ warunkach rzeczywistych. Zbudowano uniwersalne narzędzie rejestrujące o szerszym zastosowaniu niż rejestracja parametrów pracy silnika. Opracowanie rozwiązania umożliwito uzyskiwanie pomiarów $i$ monitorowanie silnika w trybie pasywnym z wykorzystaniem rozproszonej architektury, które bez produkcji rejestratora bylyby trudne do uzyskania i zarchiwizowania, zwłaszcza podczas prób w locie. Slowa kluczowe: silnik, BSP, telemetria, rejestrator 


\section{Introduction}

Unmanned Aircraft Systems (UAS), commonly called drones, are gaining popularity every year. The UAS is a system whose components include an unmanned aircraft, the supporting network, and all equipment and personnel necessary to control the unmanned aircraft [4]. The basic blocks of UAS include Unmanned Aerial Vehicle (UAV) with Flight Control Module and Navigation Module, Control Station with Communication and Control. Unmanned systems are developing dynamically, and the number of functional subsystems is becoming fully automatic. Today, drones are used in both civilian and military applications. Manufacturers, noticing the potential of UAS, make attempts to build them for transporting critical items such as medicines and medical samples, and for monitoring the border and forest areas. Taking into account the increasing use of UAS, monitoring their condition is an important aspect. The engine should be under special observation because, in the event of its failure, it usually ends with the failure of the UAS. Monitoring is, therefore, a critical element of its design. Considering UAS as a special automation system, it would be necessary to use a parallel monitoring system, which may be in contradiction with restrictions on the weight of the object. UAS engines usually have a built-in telemetry system; therefore, it is advisable to consider using it for the ongoing monitoring of the UAS. If it is noted that telemetry information is used to ensure the correct operation of the engine, its undisturbed capture could also meet the conditions for monitoring its operation. Various communication techniques found in such solutions, such as single-cable, CAN, Modbus, and others, including proprietary solutions, may be a complication. An additional difficulty in such cases may be the lack of knowledge of the protocol according to which data are sent from the transmitter, often from the sensor to the receiver. These buses can also have different architectures, e.g. point-for-point (fig. 1) or peer-to-peer (fig. 2), influencing the final location of the monitoring elements.

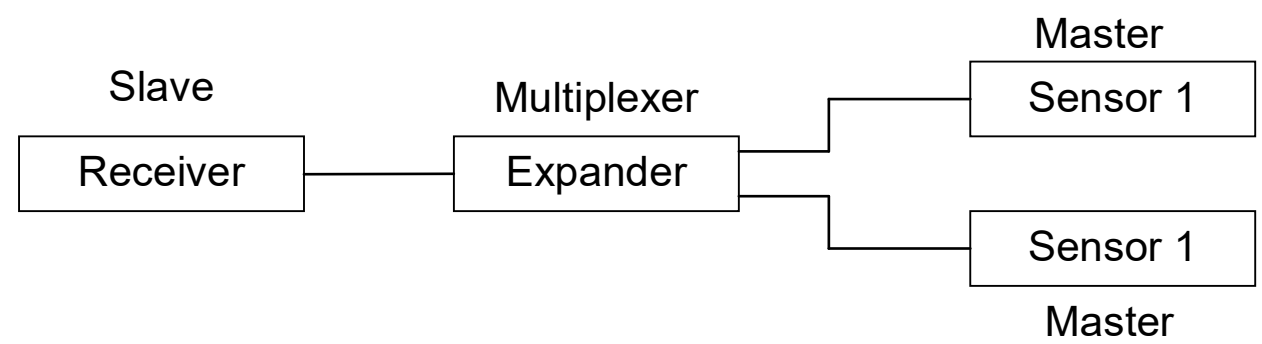

Fig. 1. Topology point to point

The article will present the advantages and disadvantages of independent control and monitoring systems and a hybrid approach using existing sensors, as shown in fig. 2. Figure 3 shows an example of a jet engine during tests. 


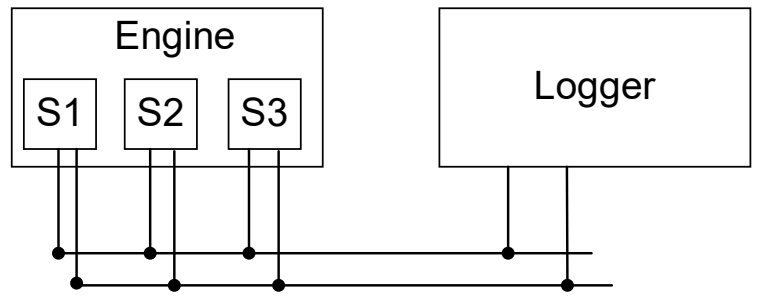

Fig. 2. The bus diagram

Transmission of signals using telemetry has found application in many disciplines [5] and, depending on their specificity, it is possible to use various transmission technologies. However, most of them are not applicable to Remotely Piloted Aircraft Systems (RPAS). As shown in Vasylenko et al. [8], although at that time a single standard had not been adopted, protocols available under the Lesser General Public License (LGPL) license, e.g. MAVLink, were also developed. An alternative to them is, for example, JETI, which is a proprietary protocol (company: JETI model, s.r.o.). Regardless of the protocol, it is important to minimize the transmission bandwidth. It should be noted that the transmission channel in the transmitter-receiver system has a limited speed [7], and this speed is relatively low. The best example of this is presented by Zebrun [9], which shows that longrange telemetry is a difficult task.

As shown by Thompson et al. [6], designing control system architectures is extremely difficult, involving a mixture of quantitative and qualitative decisions that bring together data and experience from many different design disciplines. Moreover, in RPAS, many parallel requirements, practical issues, and trade-offs need to be considered. It is worth mentioning: reliability, availability, certifiability, weight, number of connectors, etc. Taking into account the above, for the safety of RPAS in flight, it was decided to adapt the JETI solution. In this sense, the developed solution can be categorized as a smart sensor as part of a distributed control system [1].

\section{Materials and methods}

The test article used in the investigation was the development of supervision methods of the operation of the JetCat-220 engine (fig. 3) as part of tests on the ground and in flight. This engine was equipped with an integrally connected telemetry system that allows the basic parameters of its operation to be obtained: engine speed, fuel flow, exhaust gas temperature, and remaining fuel, which should be integrated with the Unmanned Aerial Vehicle (UAV) telemetry infrastructure. However, the problem was that there was no complete documentation of the engine telemetry system, so it was decided not to connect it to the UAV telemetry bus [3] as an object subject to control. 


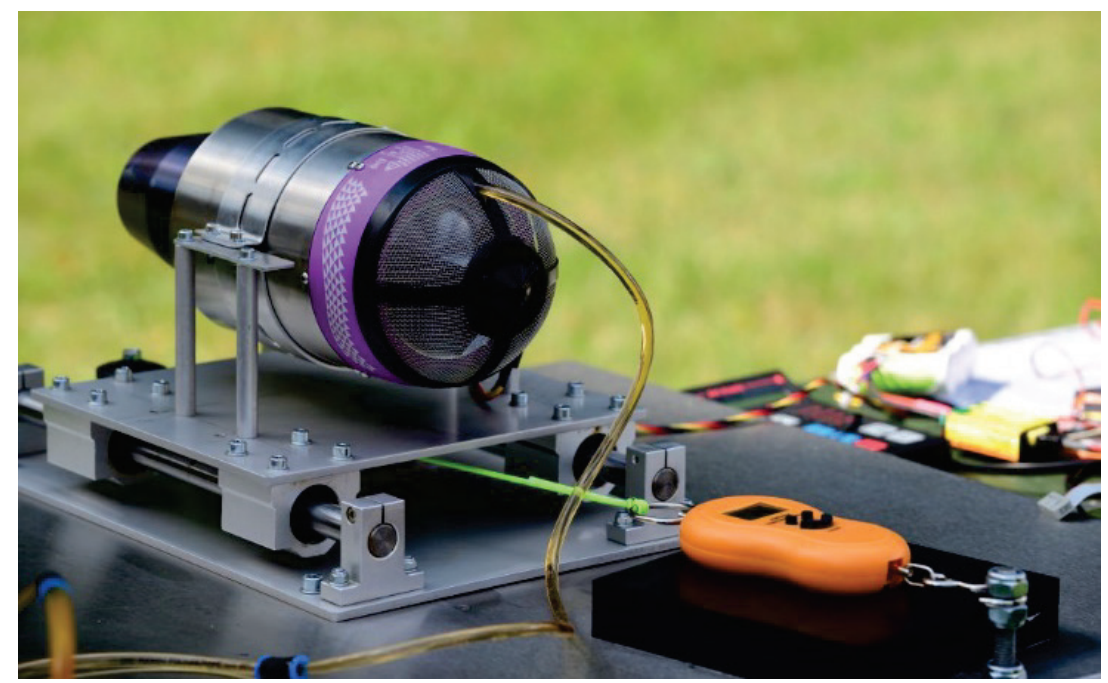

Fig. 3. The engine during the test

In view of the above, it has become necessary to develop a method of obtaining data in a way that minimally interferes with either the existing telemetry infrastructure or the engine's measuring system. During the work, it was decided to treat the engine's telemetry infrastructure as passive and to build a device, the so-called logger, that would passively collect frames sent to the bus, simulating a sensor. To build the measuring system, we used Teensy 3.5 (fig. 4). This system was characterized by high work speed (Processor ARM Cortex M4 180MHz), integration with microSD card support and full voltage tolerance $+5 \mathrm{~V}$ at logic supply voltage $3.3 \mathrm{~V}$, which ensured trouble-free connection.

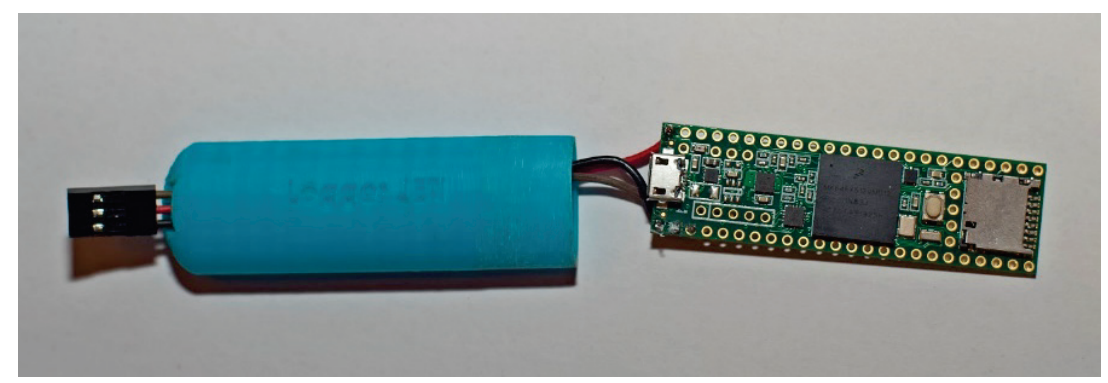

Fig. 4. Teensy 3.5 board with a dedicated protective case

Sensor software was written in $\mathrm{C}$ using the Arduino environment. A particular challenge is that communication via the JETI serial bus is carried out with the following parameters: 9600 - 9800 Baud, 9 data bits, 2 stop bits, ODD, logic 0: 1.5V (max); 1: 3.0V (min). Thus, they are parameters not typically supported by computer systems. During work on the software, it also became apparent that the 9-bit transmission is not a constant 
parameter, and the protocol itself forces sending some data in version 8 and in the 9-bit part. Due to the lack of this information in the documentation, this observation confirmed the need for an adopted approach to obtaining telemetry information from the engine in a passive way. The solution to the problem was to use a switchable communication mode (9-8 bits) supported by the Teensy processor.

After the software was written, the circuit was connected to a sensor with the known characteristics to validate the readings taken. Then, the system was connected to the engine's telemetry system (fig. 5).

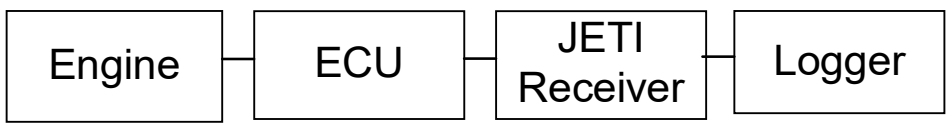

Fig. 5. Logger connection diagram

\section{Results}

The selected and programmed logger device was passively reading and decoding messages appearing on the JETI bus. The constructed and programmed system allowed for the interception of the full transmission of telemetry data, including data from the engine, as well as for their transmission and archiving. An example of successive decoded transmission frames is included in tab. 1.

Table 1

\section{Fragment of telemetry readings acquired by the logger}

\begin{tabular}{lllll} 
Frame Id & JET frame & Parameter & Value & Unit \\
\hline 1353470 & JetCat/0209a410/9 & FuelFlow & 352 & $\mathrm{ml} / \mathrm{m}$ \\
1353558 & JetCat/0209a410/10 & Altitude & 650 & $\mathrm{~m}$ \\
1353558 & JetCat/0209a410/11 & Thrust & 57 & $\mathrm{~N}$ \\
1353647 & JetCat/0209a410/12 & RpmSet & 72000 & $/ \mathrm{min}$ \\
1353647 & JetCat/0209a410/1 & EGT & 23 & ${ }^{\circ} \mathrm{C}$ \\
1353735 & JetCat/0209a410/2 & Rpm & 40000 & $/ \mathrm{min}$ \\
1353735 & JetCat/0209a410/3 & Pump & 3,35 & $\mathrm{~V}$ \\
1353824 & JetCat/0209a410/4 & EngBattery & 10,5 & $\mathrm{~V}$ \\
1353824 & JetCat/0209a410/5 & EngCurrent & 1,2 & $\mathrm{~A}$ \\
1353912 & JetCat/0209a410/6 & BattCapa & 0 & $\mathrm{mAh}$ \\
1353912 & JetCat/0209a410/7 & State/Flags & 0 & \\
1354001 & JetCat/0209a410/8 & RestFuel & 100 & $\mathrm{ml}$ \\
1354001 & JetCat/0209a410/9 & FuelFlow & 352 & $\mathrm{ml} / \mathrm{m}$ \\
1354089 & JetCat/0209a410/10 & Altitude & 650 & $\mathrm{~m}$
\end{tabular}


From the data obtained in this way, it was possible to determine the nature of the engine operation during its test and to verify the relationship between engine speed vs. fuel flow $v s$. exhaust gas temperature vs. remaining fuel (figs. 6-9).

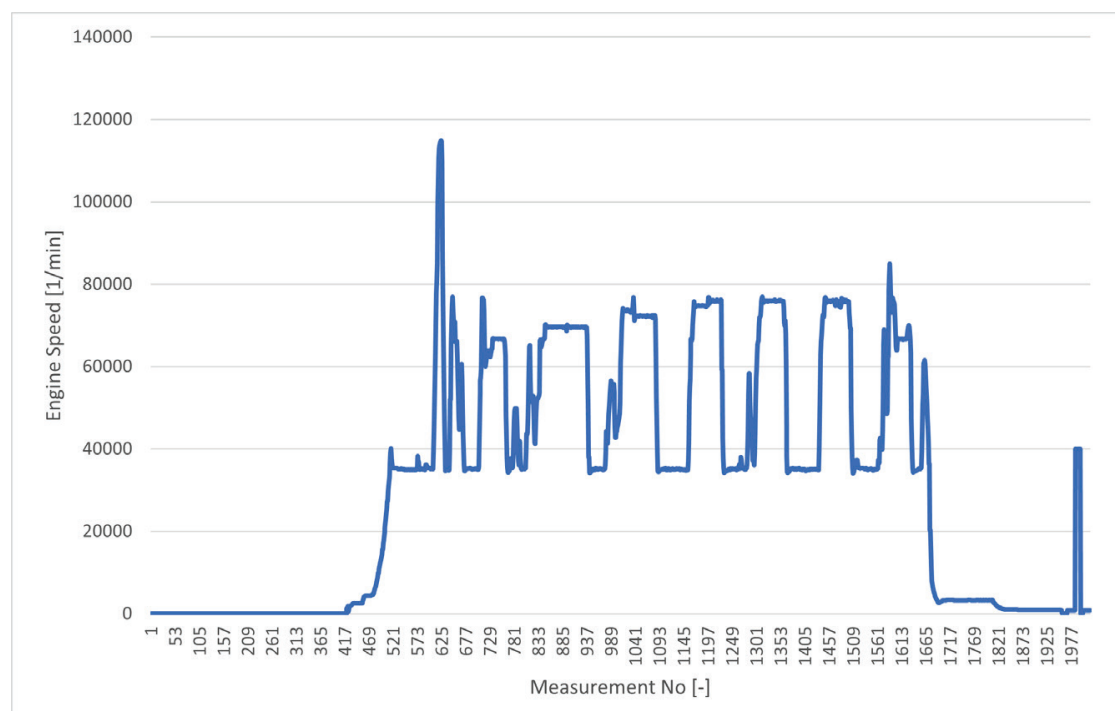

Fig. 6. A sample registration of engine speed

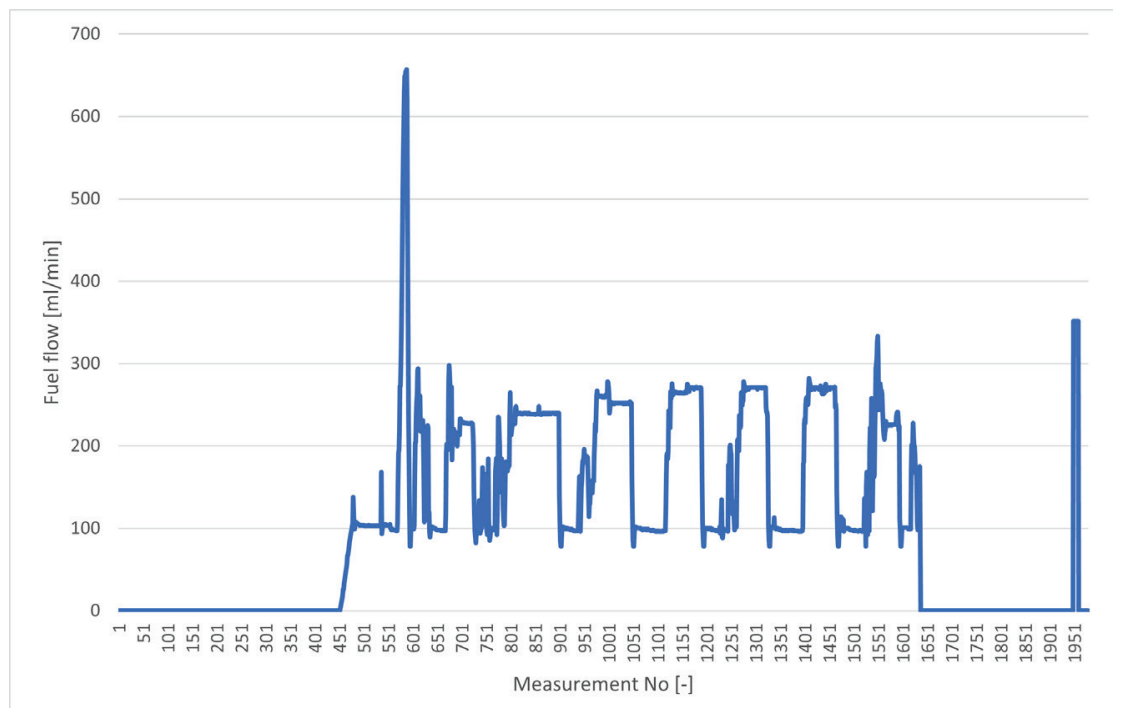

Fig. 7. A sample registration of fuel flow 


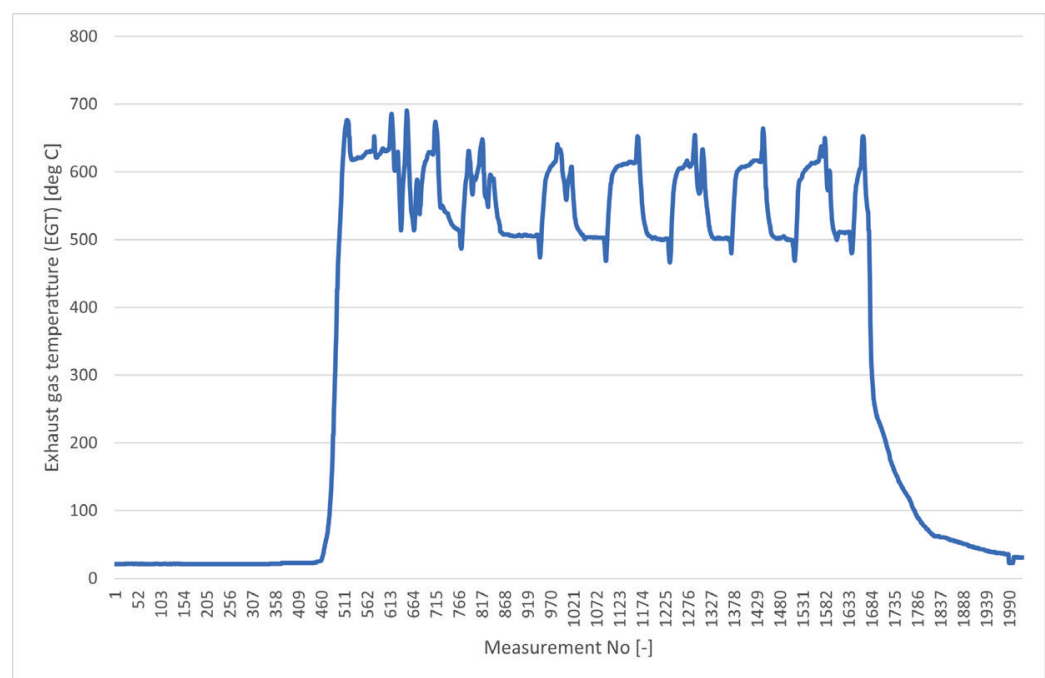

Fig. 8. A sample registration of exhaust gas temperature

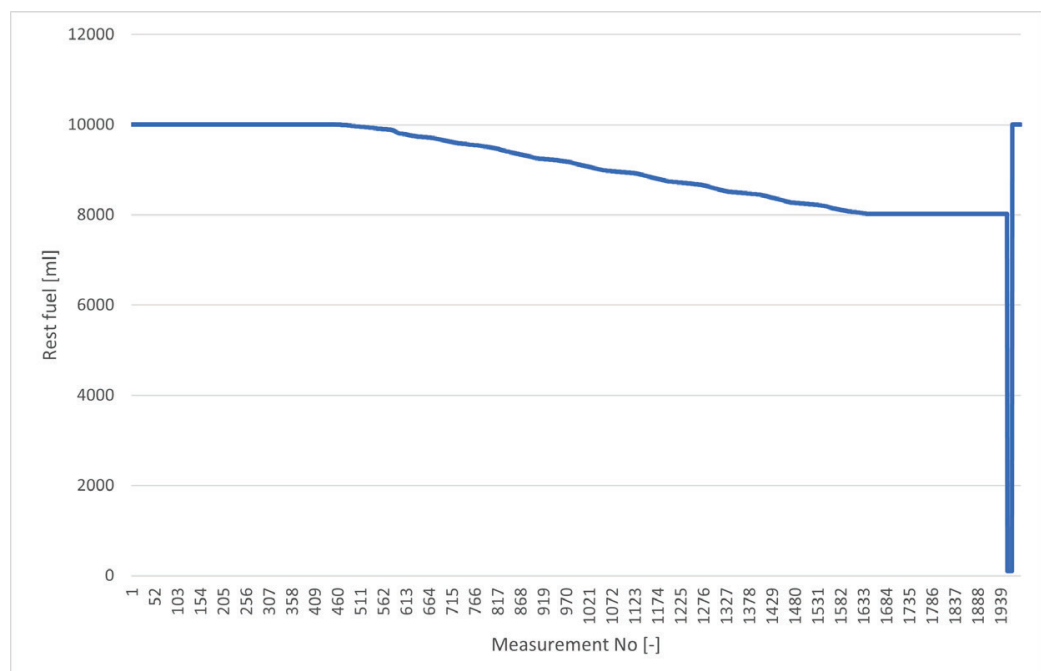

Fig. 9. A sample registration of the remaining fuel

\section{Discussion}

The passive logger, which was the electronic system that was built and programmed, allowed us to collect engine performance characteristics. As it can be seen, the relation between engine speed vs. fuel flow vs. exhaust gas temperature has the nature of a similarity 
relationship that differs essentially not so much in the nature of the work as in the achievable values. The correlation between the signals of the variables was analyzed using the Spearman correlation (tab. 2). As the fuel consumption increases, the RPM increases and the temperature of the exhaust gas increases, and the remaining fuel value decreases.

Table 2

\section{Correlation between measured values}

Spearman correlation

Marked wsp. correlations are relevant with $\mathrm{p}<0.05$

\begin{tabular}{|l|l|l|l|l|}
\hline Parameter & FuelFlow & Rpm & EGT & RestFuel \\
\hline FuelFlow & 1,00 & 0,92 & 0,78 & $-0,23$ \\
\hline Rpm & 0,92 & 1,00 & 0,80 & $-0,42$ \\
\hline EGT & 0,78 & 0,80 & 1,00 & $-0,37$ \\
\hline RestFuel & $-0,23$ & $-0,42$ & $-0,37$ & 1,00 \\
\hline
\end{tabular}

The logger system can be used both during ground tests to collect engine performance characteristics and in flight as a form of, e.g., a black box for subsequent assessment. Considering the fact that during the tests, the system recorded the readings from 12 sensors, which could then be analyzed after the flight, this proposal seems fully justified. In a later stage of work, the developed telemetry system will serve as a module for the Health Use Monitoring System (HUMS) currently being developed [10]. Its further expansion will require a software change.

\section{Conclusions}

The development of what allowed to record the measurement characteristics is important from the point of view of the engine. More importantly, it occurred without any active interference with the engine system, which, with fragmentary documentation, could lead to an unintentional change in its operating parameters. The developed solution is universal and can be used with motors equipped with integrated telemetry systems compatible with the JETI bus and in applications developed by the Air Force Institute of Technology (AFIT) for the use of jet propulsion. For many years, AFIT has been developing unmanned jet powered aerial target systems that are used in military applications.

By using a smart sensor, the possibility of expanding the system towards distributed engine control was verified. Engines used for UAVs smaller than $150 \mathrm{~kg}$ are usually dedicated to modeling, hobby, or sports applications. Before using these engines for military applications, they should be tested on the ground [2] and in flight. The developed solution 
allows us to obtain data about the engine during flight tests. This is important, because, in flight, for safety reasons, we cannot interfere with the UAV engine control system.

The results obtained and the experience gathered as a result of this issue will be used to develop HUMS dedicated to unmanned solutions.

This paper was presented at the AVT-357 Research Workshop on Technologies for Future Distributed Engine Control Systems (DECS) organized online by the NATO Science and Technology Organization on 11-13 May 2021.

\section{References}

1. Culley D.E., Paluszewski P.J., Storey W., Smith B.J.: The case for distributed engine control in turbo-shaft engine systems. NASA/TM-2009-215654, AHS 2009.

2. Dudziak D., Buczkowska-Murawska T., Żokowski M.: Assessment of the unmanned aircraft system's airworthiness in the aspect of certification. Scientific Journal of Silesian University of Technology. Series Transport, Vol. 108, 2020, DOI 10.20858/sjsutst.2020.108.3.

3. JETI model, JETI Telemetry communication protocol, http://www.jetimodel.com/en/Telemetry-Protocol/JETI-Telemetry- CommunicationProtocol/, access 18.04.2021.

4. Maźeikis E.: AAP-6 - NATO Glossary of Terms and Definitions. 2019.

5. Misurec J.: The Possibilities of Data Communication for Telemetry Systems in Energetics. International Journal of Advances in Telecommunications, Electrotechnics, Signals and Systems, 2012, DOI 10.11601/ijates.v1i1.3.

6. Thompson H.A., Fleming P.J.: Multi-disciplinary optimisation of distributed aeroengine control system architecture. Copyright@IFAC Automatic Control in Aerospace, 1998.

7. Tristancho J., Barrado C., Mansilla S., Pastor E.: A telemetry modelling for intelligent UAV monitoring. 7.C.1-1. 2009, DOI 10.1109/DASC.2009.5347421.

8. Vasylenko M., Karpyuk I.: Telemetry System of Unmanned Aerial Vehicles. Electronics and Control Systems, 2018, DOI 10.18372/1990-5548.57.13244.

9. Żebruń K.: Łazik Perseverance już nadaje z Marsa - kto na Ziemi odbiera te dane i w jaki sposób?, https://www.benchmark.pl/testy_i_recenzje/mars-perseverance-komunikacja-z-ziemia.html, access 18.04.2021.

10. Żokowski M.: Autodiagnostics for Remotely Piloted Aircraft Systems, Conference: Mechatronics Systems and Materials (MSM), 2020,

DOI 10.1109/MSM49833.2020.9201641. 